\title{
Emergent Practices of an Environmental Standard
}

\author{
Isabel Shaw \& Ritsuko Ozaki \\ Accepted to be published in Science, Technology and Human Values \\ Online First - DOI: 10.1177/0162243915589765
}

\begin{abstract}
Recent climate change statistics attribute over a quarter of carbon emissions to residential energy use in the UK. To address this, a building standard (Code for Sustainable Homes) was introduced to aim to reduce levels of carbon dioxide emissions and energy consumption. This paper analyses how such an environmental standard reconfigures the socio-technological relations and practices of housing professionals that design, construct, and manage social housing. We focus on how actors engage with the standard's recommendation for incorporating low and zero carbon technologies into new buildings. We identify diverse practices that emerge from these engagements, which, we contend, have significant consequences for the working relationships of professional actors, and for renewable energy provision. By being entwined in, and generative of actors' practices, we argue that the Code becomes part of the socio-technological relationships and infrastructures that shape energy provision.
\end{abstract}




\section{Introduction}

In 2006 a government policy called the "Code for Sustainable Homes" (referred to as the Code hereafter) was launched as a building standard to aim to reduce levels of carbon dioxide and energy consumption in the UK (DCLG 2006a). The Code seeks to make all new buildhomes "zero carbon" by 2016, with a 25 per cent improvement in energy use before 2010 and a 44 per cent improvement by 2013, against the 2006 Building Regulation (Part L). It is estimated that 29.4 per cent of carbon dioxide emissions in the UK are attributable to energy used within the home (DECC 2011). A zero carbon home is intended to emit no carbon dioxide from all energy use, such as cooking, and those currently part of building regulations, such as space heating (DCLG 2006b). This paper offers new understandings into how an environmental standard - the Code - informs the maintenance and transformation of professional practices, shaping the provision of renewable energy. To do so, we analyse how one of the Code's protocols for a reduction in carbon dioxide emissions and energy consumption affects the sociotechnical relationships and practices of housing professionals that design, construct and manage social housing in the UK. The incorporation of "low and zero carbon technologies" as part of housing design is a key recommendation by the Code. We investigate how professional actors negotiate this recommendation and interact with the technologies, arguing that the ways in which these interactions inform professional practices have profound effects on renewable energy provision.

The Code "is intended as a single national standard to guide industry in the design and construction of sustainable homes" (DCLG 2006a: 4). The social housing sector is at the forefront of efforts to implement the Code's protocol because, in order to receive grant subsidy for builds, it is mandatory for housing associations to comply with the minimum requirements set out by the Code, ahead of the private sector (McManus et al. 2010: 2015). The implementation of the Code by developers is assessed according to the performance of the whole building using a points-based system. The Code is structured into nine design categories with points attributed to each depending on the performance level attained. The 
category "energy/carbon dioxide" is particularly pertinent: it sets minimum standards relating to energy and water use, and in total the category subsumes 21.4 per cent of potential points available to developers (McManus et al. 2010: 2015).

The Code measures "the sustainability of a home against design categories, rating the 'whole home' as a design package" (DCLG 2006a: 4). This rating system, however, allows those who build new homes to "off-set" one aspect of the building with another to gain accreditation (Raman and Shove 2000). The Code's assessment procedure therefore influences how materials, people and resources are arranged (see Strathern 2000; 2004) to shape environmental outcomes. Existing research identifies tensions surrounding achieving the Code's targets, highlighting: the conflicting practices and priorities of social housing budgets and the cost of meeting the Code's standards (McManus et al. 2010; Osmani and O'Reilly 2009); and competing expertise and the emergence of new professional positionings (particularly of architect and engineer relations) of actors involved in building design (Fischer and Guy 2009; see also Aibar and Bijker 1997). These tensions emphasize that standards are not neutral or rational entities that simply act "to unite means and ends" (Wedel et al. 2005: 37).

Indeed, scholars from sociology and Science and Technology Studies (STS) argue against "techno-rational" (Guy and Shove 2000) approaches to energy and the built environment, which encourage a technologically deterministic approach towards energy efficiency. The Code is criticized for promoting such a view by seeing the issue of carbon and energy reduction as one that is amenable to universal technological solutions (Guy 2006: 646). The Code's design category "energy/carbon dioxide," for example, grants points for the installation and use of technologies such as "environmentally friendly" mundane (e.g. refrigerators) and low and zero carbon (e.g. solar thermal panels) technologies. By focusing exclusively on the construction of the building and the technologies contained therein, the sociotechnical infrastructures, practices and services in which it is bound up with are sidelined (Chappells and Shove; Fischer and Guy 2009; Guy 2006; McManus et al. 2010: 2014; McMeekin and Southerton 2012; Shove 2003; Southerton 2006; Spaargaren 2011) van 
Vliet 2004; Wilhite 2005). As van Vliet (2004: 73) puts it, "[buildings] do not stand alone" (see also Gieryn 2002). To remedy these shortcomings, Guy (2006) argues:

"[To] understand buildings we must trace the characteristics of the 'actor world' that 'shapes and supports' their production (Bijker et al. 1987: 12). Adopting this perspective would mean relating the form, design, and specification of buildings to the social processes that underpinned their development. So, although two identical buildings... may well appear physically and materially similar, investigation into their respective modes of production... may reveal profoundly different design rationales, which in turn might help explain variations in energy performance" (Guy 2006: 653).

Surprisingly, despite such calls for a relational understanding of the actors, processes and practices that shape the materiality of buildings and energy performance and consumption (see Guy and Yavena 2008), little attention has been given to the situated ways in which the Code informs professional practices involved in the design, construction and management of environmentally sustainable housing. Such an endeavour has great significance for understanding how emergent practices affect the potential for renewable energy provision. We therefore pay attention to how different forms of "relatedness" emerge between actors and policy-recommended low and zero carbon technologies with consideration to the contexts, materialities and practices of those implementing them (Gell 1998; Suchman 2005), and identify divergent practices that are created according to competing work priorities. In doing so we shed light on how professional practices and relationships are both maintained and change as they are negotiated through situated professional and technological interactions and demonstrate how these have implications for energy provision. By using the literature on standardisation and practices we offer new insights into how standards affect practices, of which there exists little consideration to date.

\section{Theoretical Framework}


Despite an intense critique levied at technologically deterministic approaches to energy and the built environment (e.g. Guy 2006; Guy and Shove 2000; van Vliet 2004), scant attention has been given to understanding how the Code informs housing professionals' practices. We argue that the Code is not separate from these practices and their material infrastructures that shape renewable energy provision. Crucially, it is constitutive of them as it is negotiated in and through actors' practices affecting how energy is provided. This point is important, as current policy literature narrowly focuses on the potential benefits of, and limitations to, the Code's "techno-rational" methodology.

To understand how professional practices are transformed through the mediation of the Code, we bring two bodies of literature together: standardization and practice theory. The STS literature of standardization offers us a foundation to explore how standards, such as the Code, seek to generate policy outcomes, such as a reduction in carbon dioxide emissions and energy consumption, through its implementation in specific localities. This process is, however, not a linear one; here, the emphasis on "local" implementation is key. Local actors possess “interpretive flexibility” (Pinch and Bijker 1984; see also Hogle 1995; Shapiro 1997; Timmermans and Berg 1997) in how they engage with a recommended protocol.

Timmermans and Berg (1997) underline how the supposedly universal character of a standard is inherently ambiguous, arguing that standards emerge from a distributed and highly negotiated process. Indeed, despite the Code's universal methods and targets that are intended for building developments across the UK, the actors, sociotechnical relationships and housing schemes, are contingent and diverse.

We conceptualize standards as containing a "script" (Akrich 1992) that anticipates the actors and activities it will engage (Timmermans and Berg 1997); and yet, a script is not deterministic and can be appropriated and shaped by local conditions in which the standard is situated. As a way of "doing things," this script seeks new practices, altering established ones; but in order to do so, any new protocol must build on existing ways of doing things (ibid: 274). The actions that follow the standard's script are therefore far from prescribed and 
uniform. The concept of "local universalities" emphasizes this point: "universality always rests on real-time work, and emerges from localized processes of negotiations and preexisting institutional, infrastructural, and material relations. 'Universality', here... no longer... implying [implies] a rupture with the 'local', but transforming and emerging in and through it" (ibid.: 275). This work underscores two key points: first, the negotiation of any standard is accomplished in action and is not a prescribed process; that is, local actors possess flexibility in how they interpret a protocol with potentially diverse and conflicting outcomes. Second, this negotiated process is distributed amongst human and non-human actors as a protocol becomes interwoven with, and transforms, existing practices and objectual relations. Objects therefore play a key role in the conduct of professional practices; and this is where our second body of literature, the social theory of practices, comes into play. Actors not only human, but also non-human - are involved in performing practices (Schatzki 2001). Focusing on materiality, practice theory highlights how practices are "embodied, materially mediated arrays of human activity... [and] understanding specific practices always involves apprehending material configurations" (ibid.: 2-3). Schatzki's (2001) notion of practices emphasizes that technological objects play a crucial role in the maintenance, transformation and re-constitution of knowledge, skills and relationships in the enactment of social practices. Latour (1988), for instance, shows how everyday instruments in the science laboratory play a crucial part in the transformation of skills and thus what counts as scientific knowledge. Objects thus actively participate in shaping sociotechnical relationships and order skills and knowledge through their active role in the development of collective practices (Preda 1999). Material infrastructures are negotiated through engaging with standards (Timmermans and Berg, 2007), but crucially, the literature on practices has less to say about how standards are negotiated to shape practices.

Barry's (2001) notion of a technology “as an arrangement" is useful to conceptualize the distributed sociotechnical relations involved in the implementation of a standard. A technology is conceptualized not as a singular device, but as an arrangement of parts that generates social ties with other actors (see also Latour 2005): 
"The idea that a non-human device or instrument can somehow work autonomously of its multiple connections with other (human and non-human) elements (language, bodies, minds, desire, practical skills, traditions of use) is a fantasy... Material (and immaterial) objects produce effects, depending upon how they are related to, the forms and circumstances of their use, and the sites and circumstances within which they are situated. Effects emerge from a combination of persons and materials" (Barry 2001: 9, 11).

In this view, a standard, such as the Code, can create transformative effects in so much as it embodies knowledge about "how thing should be done" and participates in "knowledge-inthe making" (Preda 1999: 353). As Leigh Star (2010: 604) reminds us, standards comprise "a set of work arrangements that are at once material and processual," which seek to classify and organize the social and technical worlds they act upon. The question of how actors act to manage carbon reduction and energy consumption through housing design, of which technology installation and management is a significant part, demands an appreciation of how professional actors' practices and the Code's protocol are "made to work" in relation to diverse localities, conditions and sociotechnical relationships (see Bowker and Star 2000). Actors employ their interpretive flexibility to manage both a standard's requirement and existing local relationships through which they conduct their work. Combining the literatures on standardization and practices therefore allows us to offer new understandings into how standards, such as the Code, affect the maintenance and transformation of professional practices. This theoretical framework enables us to focus on practices involved in implementing the design category "energy/carbon dioxide" of the Code, affording us detailed insights into how practices and relationships are maintained and change as they are negotiated through situated professional and technological interactions. We identify multiple emergent practices by examining how the incorporation of low and zero carbon technologies into new homes is negotiated by social housing professionals as part of conducting work practices. The Code's protocol is incorporated into, and re-configures, practices of housing design, 
construction, and management. These practices have diverse consequences for the ways in which energy services are formed and provided.

\section{Research}

The study has been conducted in collaboration with a large housing association that develops and maintains social housing schemes in London and South-East of England. The research is informed by 20 in-depth interviews carried out over a period between June 2010 and August 2011 with professionals involved in designing, constructing and managing housing schemes that were developed under the directive of the Code (see Table 1).

\section{Table one about here}

Twenty semi-structured interviews were carried out with "front-line" actors: architects, a building contractor, development managers, maintenance managers, sustainability consultants ${ }^{\mathrm{i}}$, an employer's contractor, and council employees. They were involved in the development of housing schemes that had one of the following technologies installed: photovoltaic (PV) cells or biomass Combined Heat and Power (CHP) technology. Interview contacts were sought from actors working within and for the housing association. For this, judgement sampling (Saunders et al, 2009) was used to identify interviewees, whereby the selection was made with the assistance of the housing association. The approach enabled us to access professionals involved in the design, development and management of housing schemes affected by the Code, bringing us insights into the varied practices carried out by professionals and their immediate working relationships. Indeed, our interviewees had a particular interest in the question of how diverse professionals approached the Code's recommendations as part of housing design, construction, and management, as each department worked relatively independently from each other. This enabled us to consider if and how these technologies differently affected professional practices and relationships. 
A detailed information sheet was provided to each participant before the interview. This explained the aims of the project, that the interview was voluntary, and that they could withdraw from the project at any time without explanation. We have ensured participant confidentiality and anonymity; only the researchers involved in the project have access to the interview transcripts.

In the first phase, we examined how different professionals approached and implemented the Code by focusing on how their varied practices were consolidated, given their diverse work priorities and engagements with technologies. This line of questioning was attentive to how their work was carried out in relation to the materiality of their work practices: for instance, architects work on design plans ("planning statements") to gain building approval, whilst development and maintenance managers engage in installing and managing the technologies.

Interviews were coded using NVivo software to manage data and capture emerging themes (Thomas 2006), which then informed questions used in the second phase of interviews. We did not use pre-existing themes to frame the codes; rather, we adopted an open-coding approach. This helped us refrain from starting with our own assumptions about how actors engage with low and zero carbon technologies, allowing emerging themes to shape our analysis. From these themes we identified further lines of enquiry to use in the second phase: for example, how low and zero carbon technologies affected design processes; how these technologies were mobilized to demarcate professional jurisdiction; and the politics of making materials and technologies visible and accountable to the Code. These themes helped us explore the creative and varied ways in which actors interpret and transform their existing sociotechnical relationships and the Code's protocol.

Additional insights into the processes of the Code's implementation were gained through informal discussions with actors working for the housing association, such as its Environmental Sustainability Officer, during the course of arranging fieldwork, and our attendance of internal events from September 2009 to August 2011. These events include: a day workshop that discussed the challenges of incorporating low and zero carbon 
technologies into housing developments and their impact on work practices, and an introductory "walk-through" event to a new housing development that had installed low and zero carbon technologies with housing association employees.

\section{Materializing an environmental standard: diverse practices}

The Code's target is to reduce carbon emissions and energy consumption through the use of design categories, which contain recommendations for design practice and set negotiable parameters of "acceptable" practice (Bowker and Star 2000: 39) with the Code's methodology (Table 2).

\section{Table two about here}

We identified three central practices that transpire from actors implementing the Code's protocol and interacting with "low and zero carbon technologies" in designing, constructing and managing a building: (a) practices of alignment, (b) practices of strategic mobilization, and (c) practices of reconfiguration. These diverse practices are presented below, showing how actors attempt to change as well as retain their existing work practices. We detail the local conditions of these practices, emphasizing the strategic ways in which actors and technologies become re-configured. Low and zero carbon technologies act as resources for actors to creatively manage their professional relationships and work jurisdiction, as well as influential agents of sociotechnical change. All three practices emerge from different stages of housing development: planning, installing and managing low and zero carbon technologies respectively. As varied dynamics at different moments in the development process, they show how different professionals sustain relations between themselves through the implementation of the Code's recommendations; and we contend that the resultant practices have significant consequences for working relationships and renewable energy provision, which we outline below. 


\section{a) Practices of alignment: negotiating the Code's recommendations and planning}

The Code shapes different actors' practices, influencing possibilities for practical action. One distinct practice is the practice of alignment. That is, professional actors "align" their choice of technologies with the Code's requirements, building designs, and their competitive activities, to gain planning consent from local councils. The attendant practices of demonstration and visibility are central to this practice whereby actors symbolically represent the alignment of the Code with the chosen technologies. As a result of professional actors performing practices of alignment, demonstration, and visibility, we argue that considerations over a building's wider sociotechnical relations and future use are ignored. We demonstrate below how this has important implications for energy provision.

Local councils set their own targets for environmental sustainability that are necessary for developers to meet to gain planning permission, and the Code offers an assessment framework to achieve this. Because the Code's assessment is performance based (Raman and Shove 2000), developers may implement one aspect of the Code over another as long as they accrue enough points to attain the necessary level determined by the local council's environmental sustainability criteria. Cost is a significant factor shaping how the Code is implemented, such as the choice of low and zero carbon technologies. Indeed, often housing associations collaborate with private developers to construct housing (known in the UK as "section 106 agreements"). In these contexts, private developers are influential in determining which technologies are chosen so that costs are managed and commercial priorities are met, such as maintaining their profit margins. Actors align low and zero carbon technologies carefully with the Code's methodology and assessment procedure. The attendant practice of "demonstration" is key to this effort. This is explicit in the following quote that reveals how such technologies are considered as part of making a building design: 
We always start with what the target is and the target can come from policy. Obviously the UK has targets... which are filtered down into each local authority's planning departments and their planning guides... What we have to do is look into the policy documents to see exactly how that target is worded because you get a very different answer; you choose a different technology depending on what the actual wording is... So it could be... "10 per cent of renewable energy" or it could be "10 per cent energy provision, energy saving, carbon dioxide saving"... It's ultimately the planning officer who should be looking into our documents and seeing whether we've tied up with what their policy requests... The different technologies perform differently under the different policies. (Sustainability Consultant, S)

Sustainability consultants provide strategic advice to architects and engineers about the choice of technologies in order to comply with the Code's requirements. According to a consultant: "If there's a high water requirement for heating, you'd obviously put solar thermal or focus on boilers and things like that. If there was [a] high electricity [requirement] you'd focus on PV [photovoltaics]" (Sustainability Consultant, S). The choice of technologies is influenced by the Code's guidelines that are incorporated into planning requirements by local councils. Furthermore, housing associations often receive government funding for their developments, which also places conditions on the planning process to include low and zero carbon technologies as part of a building's design, fulfilling the Code's criteria.

The practice of aligning the Code's recommendations with the incorporation of technologies in the design phase does not fully prescribe actors' activities. Mentioned earlier, new buildings are assessed on the performance of the whole building, allowing actors to substitute one aspect of the building with another to gain accreditation (Raman and Shove 2000) from points allocated to the different design categories. This method of assessment affords actors interpretive flexibility in translating the Code's guidelines: 
It's a lot more flexible now [compared to the Code's predecessor], and it's open to translation, and so if you can prove to the assessors or to the planners that okay, you haven't got this, but you've done this to make up for it, they're a lot more receptive. (Architect, A)

In spite of such flexibility there are compromises to fulfilling commercial priorities and the Code's requirements. A central tension emerges from alignment practices: the separation of a building from its wider sociotechnical relationships and future use. This is shown in the quote below where a building's use is neglected in favour of "making visible" that the building materials are aligned with the Code's point based system for accreditation. This tension transpired in a development where photovoltaic cells (to generate electricity) are installed onto the roofs of a housing development to meet planning conditions. Yet, the quantity installed cannot generate enough "useful" electricity to be of potential benefit to residents:

The size of the panels on the first bunch of houses was so small... It wouldn't generate that much electricity. It's no good saying to people, you've got solar panels but, by the way, it's probably only going to generate enough to run a couple of light bulbs.

(Maintenance Manager, L)

Asked why photovoltaic cells were installed in such developments despite users not being able to capitalize on their potential for energy renewables, an architect who worked on this development remarked: "They look fantastic, they're sexy; they look really nice" (Architect, B). Making visible the Code's requirements for sustainability with a building's design make photovoltaic cells a popular choice to manage tensions that other technologies generate. In another example, a contractor describes how the incorporation of a biomass boiler (fuelled by wooden pellets) into a building design presented difficulties because of the technology's extended networks (e.g. pellet suppliers) and practices (e.g. delivery of the pellets, and feeding the boiler with the pellets). Eventually, photovoltaic technology was 
chosen over a biomass boiler because it could still offer the credits needed to meet the Code, whilst not overly challenging the building design:

With the Code assessor we changed the boiler (for)... a conventional boiler, but just put more PV [photovoltaic] and solar [panels] on the roof to offset [the carbon dioxide requirement]... [Photovoltaic cells] are just mounted on the roof, the roof stays the same construction, so what you are doing is just adding to it and then just piping or wiring [it] into the heating or hot water system. So the benefit of that is... you get more credits from the Code. (Building Contractor, C)

In the above example, the overriding need to comply with the Code resulted in the installation of photovoltaic cells. The choice of this technology over a biomass boiler reflected the challenges presented by the boiler's extended network and practices which made maintaining and managing the boiler post-build difficult, as well as the expense that would incur with radical changes to the building design. The ability to accrue sufficient points to meet the Code's targets, and that photovoltaic cells are more easily installed whilst not overly challenging a building's design, make this technology a popular choice. As demonstrated in these examples, photovoltaic cells visibly represent "environmental sustainability" to Code assessors.

Above we have seen how actors seek to align the low and zero carbon technologies with the building design, the Code's assessment criteria, and their work relations. The agency of the Code is not total (see Hogle 1995; Shapiro 1997; Timmermans and Berg 1997); actors mobilize the alignment practices to meet work priorities, such as getting planning consent, or to maintain current work practices. To make evident the Code's implementation is essential to housing professionals. The attendant practices of demonstration and visibility are crucial to, and interwoven with, their practices of alignment. In an effort to create universal representations of a "sustainable" building in design plans, actors "manage out" complexities such as potential use and wider sociotechnical relationships. This replicates the Code's 
definition of environmental sustainability, which promotes a technology-driven solution to energy reduction (Chappells and Shove 2004; Guy 2006; van Vliet 2004; Wilhite 2005). This definition is purposefully appropriated by professional actors to meet the commercial need to gain planning consent from local councils. Our analysis thus shows how the Code's influence on practical action is shaped by its strategic alignment with the commercially competitive ambitions of actors to get approval from the Code to then develop houses. From these alignment practices tensions emerge that have implications for renewable energy provision. For instance, not installing an adequate amount of photovoltaic cells diminishes the potential to produce free electricity despite fulfilling the Code's requirement.

Next, we examine how actors artfully appropriate low and zero carbon technologies to manage professional relationships and delineate knowledge and expertise. We focus on the processes of technology installation and management to explore how professional and technological relationships are assembled, with further consequences for renewable energy provision.

\section{b) Practices of strategic mobilization: delineating expertise and jurisdiction through installing a partial photovoltaic (PV) system}

In strategic mobilization, the second distinct practice, professional actors strategically appropriate technologies to help distinguish their accountability and jurisdiction. We show how actors resist change in attempts to keep in place their existing working relationships by appropriating diverse sociotechnical possibilities (Barry 2001) to assemble and manage their practices and relationships. The example discussed below demonstrates how this leads to the incomplete installation of a sustainable technology, thus limiting the possibility for energy provision.

Risks associated with technology installation include potential technological failure and repair, of which a contractor (often responsible for the cost of a build) does not want to be held accountable. In the case of a photovoltaic system a contractor procures specialists to 
install photovoltaic panels to manage these risks. This helps delineate boundaries between technologies, professionals, and work responsibilities:

If you employ a mechanical and electrical contractor... and then a specialist doing the renewables and at the end of the job it doesn't quite work... well, whose fault is it? If you go through one contractor and they then employ the specialist, it means that you've only one person to go back to should it not work. The specialist will buy and install the panels on the roof and take cables into the roof space. And then the electrician will perhaps come in and provide his inverter and his box, and then one or other will join the two together to make sure it works. (Building Contractor, C)

Mobilizing materials, such as panels and cables, these professionals "map out" areas of expertise by using the technologies to hand. These actions, however, do not always produce favourable end results envisaged by the Code. The installation of photovoltaic panels can greatly influence a housing association's relationships and their work practices. In the next example, the housing association appropriates photovoltaic technologies and the installation process to manage their relationship with tenants and electricity suppliers. To generate renewable electricity, the photovoltaic system requires the installation of cells onto the roof of a development. Moreover, to try to capitalize solar generated electricity feedback smart meters are fitted inside the properties. Theoretically, the meters allow the residents to quantify the electricity created, and therefore the amount they can sell back to the grid. However, here the feedback meters are not installed. According to a maintenance officer:

[The] catch 22 is that none of the feedback meters are installed because they [residents] need to speak to their supplier. And if they managed to get them, however, they cost about $£ 400$ $£ 500 \ldots$ realistically, most of our residents wouldn't have that sort of money to outlay in a property... It's down to each person [resident] to set up an account with whoever their supplier is going to be... [We] tend not to do it, as we don't deal with the energy suppliers... 
Unless they have this meter fitted they're basically not able to use the energy they're generating. (Maintenance Officer, L)

The photovoltaic system is only partially installed so that the housing association does not have to manage the utility provision of electricity for residents. This example shows how the incomplete installment of a technological system enables the housing association to resist change and keep in place existing relations with its tenants and energy suppliers and maintain its work practices. The imagined environmental and financial benefits of the photovoltaic technologies exist only as potential because the installation of the cells is partial.

In the next section, we discuss how low and zero carbon technologies "bite back" (Barad 1998, Suchman 2005) powerfully reconfiguring the housing association's relationships and practices - transforming their role as a landlord into a utility service provider.

\section{c) Practices of reconfiguration: managing biomass Combined Heat and Power (CHP)}

Alternative technologies enable different possibilities for the reconfiguration of the relations between professional actors, tenants, and low and zero carbon technologies by influencing professionals' practices. In contrast to the previous practices, actors are not always able to use these technologies strategically to manage working relationships and practices, which we call the practice of "reconfiguration." A case in point is a housing association's installation of biomass CHP in a new block of flats. Biomass CHP generates heat and power by the incineration of biomass materials, such as wood pellets. It is a centralized heating and hot water system that runs using one boiler for an entire building. Actors who design, construct and manage housing developments that incorporate CHP acknowledge that it challenges work practices. From a contractor's perspective:

As soon as you go air source heat pumps, ground source heat pumps, and biomass boilers, you're changing the whole design philosophy [our emphasis]. (Contractor, C) 
CHP technologies bring with them complex sociotechnical infrastructures that influence the design and use of a building. In planning a building development, for instance, utilizing CHP considerations include: how the boiler will be regularly serviced with wood pellets, establishing a stable supplier of biomass material, vehicle access to the building for pellet deliveries, and the creation of distinct spaces within the building for the technology to operate (e.g. a central boiler room). In the quote below, not only does the installation of CHP technology influence the design of the building, it also transforms the housing association's relationship to their tenants from being solely a social housing landlord to acting as a utility provider. According to a development manager:

In the past, where you have non-communal heating systems... [utility suppliers] have a contract with the resident to supply them... and the resident has to pay them, and if there's any problems with the supply it's the supplier's fault and if there's any problem with the payment it's the resident's fault. But where we have a communal system, heating or power system, suddenly there isn't a utility supplier, we have a utility supplier and then we supply to residents. So we are effectively becoming a utility supplier. (Development Manager, H)

The centralized and communal way in which CHP technology distributes energy throughout the building dramatically and forcefully redefines the housing association's relationships to their residents, practices, expertise, and jurisdiction. Not only does the housing association now manage tenancies, they also check meters, source energy, bill residents, and manage resident debt. For the housing association, supplying energy is a very different obligation to acting as a landlord. Tensions emerge from these two roles, for example, in circumstances where residents have a perfect tenancy record but owe money for energy supply: 
We can't chuck them out on the basis of tenancy obligations. We don't really want to be shutting peoples' heating and hot water off, and in fact, in this case it is very difficult to do that because you have to get into peoples' flats to turn it off. (Development Manager, H)

Biomass CHP technology transforms the housing association's existing relationship to its tenants and energy suppliers by reconfiguring actors' practices and responsibilities (see also Law and Singleton 2000). The use of CHP thus creates new social and technological arrangements in which actors are re-positioned, requiring of them to adapt to significantly different professional relationships and work practices. The implementation of the Code's protocol acts forcefully to change actors' practices in unexpected, and in this case, undesired ways.

From these examples we can see how a standard's protocol is distributed amongst, and transformative of, the sociotechnical relations of actors (Timmermans and Berg 1997). This results from the incorporation of low and zero carbon technologies into housing developments with consequences for renewable energy provision.

\section{Discussion and conclusion}

This paper set out to examine how housing professionals' engagement with the Code's protocol, which recommends the incorporation of low and zero carbon technologies into the design, construction and management of new homes, shapes their varied working practices and sociotechnical relationships. To investigate how these actors and technologies interact, and consequently shaped emergent practices, we have drawn upon two bodies of literature: standardization and practices. The literature on standardization (e.g. Timmermans and Berg 1997) highlights the interpretive flexibility afforded to actors by a standard, whereby standards are negotiated in relation to local actors' pre-existing work practices and relations. The literature on practices (e.g. Barry 2001; Schatzki 2001), on the other hand, emphasizes the "material configurations" (see Barry 2001; Gell 1998; Suchman 2000, 2005) that 
constitute practices, stressing the active part that objects (technologies) play in their performance. From this view, technologies recommended by the Code can be considered as a tangible embodiment of the standard. The practice perspective therefore allows us to look at the Code's recommended technologies as being constitutive elements of everyday practices. This helps us identify how local professionals' work practices are mediated in dealing with the Code recommended technologies. By examining how these actors interact with these technologies as part of their work practices to implement the Code's protocol, we can clearly see that these technologies participate in re-constituting professional activities and relations. Combining these elements of both the standardization and practice literature has enabled us to focus in on actors' interpretive negotiation of a standard in localized settings, paying attention to the materiality of their practices.

This focus has indeed revealed the ways in which low and zero carbon technologies are incorporated into housing professionals' practices. The varied practices emerging from actors' engagements with the Code are contingent to the local conditions and dynamics of professional actors' work. We identified three key practices of (a) alignment, (b) strategic mobilization, and (c) reconfiguration. We argue that these practices are strategically resourceful and transformative; differently configured practices and sociotechnical relationships transpire, with clear significance for different forms of energy provision.

a) Practices of alignment

Low and zero carbon technologies embody diverse possibilities for re-constituting sociotechnical relations and practices. In the process of making a building design to gain planning permission, actors worked to align the Code's recommendation for the incorporation of technologies, their need to gain planning consent, and their choice of technologies. This practice of alignment enrolled the attendant practices of visibility and demonstration to make accountable the Code's implementation to the local council and assessors. The example of installing a limited quantity of photovoltaic cells that did not generate enough energy shows 
how practices of alignment are consequential for limiting the potential for renewable energy provision.

\section{b) Practices of strategic mobilization}

We also saw how actors appropriate low and zero carbon technologies to manage their relationships, professional jurisdiction, and risk. Technologies are strategically mobilized to keep in place existing practices, knowledge, and work relations by intentionally reassembling sociotechnical relationships. By installing an incomplete photovoltaic system (and delegating the responsibility of buying and installing the feedback meter to residents), for example, the housing association is able to maintain its jurisdiction as a housing landlord and its existing relationships with its tenants and energy suppliers. This has a direct influence on energy provision. Because of the expense levied at residents, the potential for the photovoltaic cells to provide a source of renewable electricity and income for the social housing residents is curtailed.

\section{c) Practices of reconfiguration}

Finally, we witnessed how biomass CHP technology asserts its agency and authority by radically re-configuring existing professional practices and dramatically altering the housing association's relationships to its tenants and energy suppliers. Transforming the housing association's work from a landlord to a utility provider, the CHP technology demands the performance of new practices: checking meters, sourcing energy, supplying fuel, and billing residents for energy consumption. This technology brings with it its own practices and sociotechnological infrastructures that initiate the assemblage of diverse knowledge, skills, and professional-technology interactions. Such interactions are not always equal or desired, thus underlining the potentially uneven and powerful influence of standards depending on the sociotechnical conditions through which a standard's protocol is negotiated. As we saw, local actors cannot always influence and control the direction of sociotechnical change enacted through engaging with the Code's protocol. 
Our detailed analysis demonstrates how professional actors negotiate recommended technologies with varying degrees of modification to their existing sociotechnical practices and relations, which, in turn, has implications for renewable energy provision with varied, and sometimes undesired, outcomes. Technologies are chosen to try to conform to the Code's criteria in accordance with locally contingent circumstances. In the examples where practices of alignment and strategic mobilization emerged, technological systems were negotiated and deployed in such a way that the Code's criteria were satisfied for accreditation and existing relations with energy suppliers and tenants were maintained respectively. On the other hand, the example of CHP biomass technology, which generated practices of reconfiguration, underscores the powerful ways in which a technology can reconfigure energy provision by creating new and challenging work practices and relationships between housing professionals and tenants. In promoting a technologically deterministic approach to energy reduction and renewal, the Code ignores these technology-professional interactions and resultant practices that impact directly on processes of energy provision. This is why the aims of the Code are not achieved.

This study makes clear that the Code's top-down, technologically deterministic approach to energy reduction and renewal is not a neutral or rational instrument that generates linear and unambiguous end results. Whether or not the Code's protocol achieves its aim of reducing carbon emissions and energy consumption in the home depends on how local actors interpret the Code and how they accommodate the recommended technologies in relation to their existing practices.

Housing providers and policy makers, as well as researchers, need to pay greater consideration to the variety of ways in which actors interact with the material infrastructures of standards, such as recommended technologies, and co-produce environmental outcomes through their diverse practices. Policy implementation requires not only the installment of recommended technologies in the homes, but also attention to the process in which a particular technology is chosen, the way it is deployed, and the sustainable effects it is 
expected to generate. We must understand how it is interpreted on a local level and how its material infrastructure is appropriated to fulfil the standard's requirements with regards to the practices and contexts in which professional actors operate. Professionals' sociotechnical practices cannot be separated from understandings of environmental change. The precise nature of how technologies and professionals become assembled has profound implications for the maintenance and transformation of practices that shape renewable energy provision. 


\section{Bibliography}

Aibar, E. and Bijker, W. 1997. "Constructing the city: the Cerda Plan for the Extension of Barcelona”. Science, Technology, and Human Values. 22 (1): 3-30.

Akrich, M. 1992. "The De-scription of Technical Objects" in Shaping Technology/Building Society: Studies in Sociotechnical Change, edited by W.E. Bijker and J. Law, The MIT Press: 205-224.

Barad, K.1998. "Getting Real: Technoscientific Practices and the Materializa-tion of Reality". Differences: A Journal of Feminist Cultural Studies 10: 88-128.

Barry, A. 2001. Political machines: governing a technological society. London and New York: The Athlone Press.

Bijker, W. Hughes, T, and Pinch, T. 1987. The social construction of technological systems: new directions in the sociology and history of technology. Cambridge: MA: MIT Press.

Bowker, G, and Leigh-Star, S. 2000. Sorting things out: classification and its consequences. Cambridge: The MIT Press.

Chappells, H. and Shove, E. 1999. "The dustbin: a study of domestic waste, household practices and utility services.” International Planning Studies. 4 (2): 267-280.

DCLG. 2006a. Code for Sustainable Homes: A Step-change in Sustainable Home Building Practice. London: Department for Communities and Local Government. 
DCLG. 2006b Building a Greener Future: Towards Zero Carbon Development. London:

Department for Communities and Local Government.

DECC. 2011. 2009 Final UK GHG Gas Emissions Data. London: Department for Energy and Climate Change.

Definition of zero carbon homes and non domestic buildings. 2008. www.zerocarbonhub.org/resourcefiles/1101177.pdf

Fischer, J. and Guy, S. 2009. "Re-interpreting Regulations: Architects as Intermediaries for Low-carbon Buildings". Urban Studies. 46 (12): 2577-2594.

Gell, A. 1998. Art and Agency: An Anthropological Theory. Oxford: Clarendon Press.

Gieryn, T. 2002. "What buildings do." Theory and Society. 31: 35-47.

Guy, S. 2006. "Designing urban knowledge: competing perspectives on energy and buildings". Environment and Planning C. 24: 645-659.

Guy, S. and Shove, E. 2000. A Sociology of Energy, Buildings, and the Environment: Constructing Knowledge, Designing Practice. London: Routledge.

Hogle, L. 1995. "Standardization across Non-standard Domains: The Case of Organ Procurement”. Science, Technology, and Human Values. 20 (4): 482-500.

Latour, B. 1988. The Pasteurization of France. Cambridge: Harvard University Press.

Latour, B. 2005. Reassembling the Social. Oxford: Oxford University Press. 
Law, J. and Singleton, V. 2000. "Performing technology's stories: on social constructivism, performance, and performativity". Technology and Culture. 41 (4): 765-775.

Leigh Star, S. 2010. "This is not a boundary object: reflections on the origin of a concept". Science, Technology, and Human Values. 35 (5): 601-617.

McManus, A, Gaterell, M. and Coates, L. 2010. "The potential of the Code for Sustainable Homes to deliver genuine 'sustainable energy' in the UK social housing sector". Energy Policy. 38: 2013-2019.

McMeekin A. and Southerton, D. 2012. "Sustainability transitions and final consumption: practices and Sociotechnical systems." Technology Analysis and Strategic Management. 24: $345-361$.

Osmani, M. and O'Reilly, A. 2009. "Feasibility of zero carbon homes in England by 2016: A house builder's perspective”. Building and Environment. 44: 1917-1924.

Preda, A. 1999. "The turn to things: arguments for a sociological theory of things". The Sociological Quarterly. 40 (2): 347-366.

Raman, S. and Shove, E. 2000. "The business of building regulation" in The Business of Greening, edited by Fineman, S. London, Routledge: 134-150.

Saunders, M, Lewis, Philip, and Thornhill, A. 2009. Research methods for business studies (5th ed.). Harlow: Person Education. 
Schatzki, T. 2001. "Introduction: practice theory" in The practice turn in contemporary theory, edited by Schatzki, T, Knorr Cetina, K, Savigny, Von E. 1-14. London and New York: Routledge.

Shapiro, S. 1997. "Degrees of Freedom: The Interaction of Standards of Practice and Engineering Judgment”. Science, Technology, and Human Values. 22 (3): 286-316.

Southerton, D. 2006. “Analysing the temporal organization of daily life: social constraints, practices and their allocation”. Sociology. 40: 435 - 454.

Spaargaren, G. 2011. "Theories of practices: agencies, technology, and culture. Exploring the relevance of practice theories for the governance of sustainable consumption practices in the new world-order. Global Environmental Change: Human and Policy Dimension. 21(3): 813822.

Strathern, M. 2000. "New accountabilities: anthropological studies in audit, ethics, and the academy". In Audit cultures: anthropological studies in accountability, ethics, and the academy, edited by Strathern, M, 1-18. London and New York: Routledge.

Strathern, M. 2004. Commons and borderlands: working papers on interdisciplinarity, accountability, and the flow of knowledge. Sean Kingston Publishing.

Suchman, L. 2000. “Organizing alignment: a case of bridge-building”. Organization 7 (2): 311-327.

Suchman, L. 2005. “Affiliative objects”. Organization 12 (3): 379-399. 
Thomas, D. 2006. "A general inductive approach for analyzing qualitative evaluation data". American Journal of Evaluation. 27 (2): 237-246.

Timmermans, S. and Berg. M. 1997. "Standardization in Action: Achieving Local Universality through Medical Protocols”. Social Studies of Science. 27: 273-305.

Vliet van, B. 2004. "Shifting scales of infrastructure provision". In Sustainable consumption: the implications of changing infrastructures of provision, edited by Chappells, H, Southerton, D, and van Vliet, B. UK: Edward Elgar Publishing.

Wedel J, Shore C, Feldman G, and Lathrop S. 2005. "Toward an anthropology of public policy". The Annals of the American Academy of Political and Social Science. 600: 30-51.

Whilite, H. 2005. "Why energy needs anthropology”. Anthropology Today. 21 (3): 1-2.

Yavena, A. and Guy, S. 2008. "Understanding architecture, accounting society”. Science Studies. 21 (1): 3-7. 
Table 1. Interviewee Profiles

\begin{tabular}{|c|c|c|c|}
\hline Job Title & Reference & $\begin{array}{l}\text { Interview } \\
\text { date }\end{array}$ & Responsibility \\
\hline Architect & A & $\begin{array}{l}\text { September } \\
2010\end{array}$ & Design of housing \\
\hline Architect & B & $\begin{array}{l}\text { October } \\
2010\end{array}$ & Design of housing \\
\hline $\begin{array}{l}\text { Code Steering Group } \\
\text { Member }\end{array}$ & C & June 2011 & $\begin{array}{l}\text { Advises on formulating the Code for Sustainable } \\
\text { Homes }\end{array}$ \\
\hline Contractor & $\mathrm{C}$ & $\begin{array}{l}\text { October } \\
2010\end{array}$ & Housing construction \\
\hline $\begin{array}{l}\text { Community Liaison } \\
\text { Officer }\end{array}$ & D & June 2011 & Resident liaison and support \\
\hline Councillor & E & March 2011 & Housing planning and development \\
\hline Councillor & $\mathrm{F}$ & March 2011 & Housing planning and development \\
\hline Development Officer & G & March 2011 & Housing development \\
\hline Development Officer & $\mathrm{H}$ & $\begin{array}{l}\text { February } \\
2011\end{array}$ & Housing development \\
\hline Development Officer & I & July 2010 & Housing development \\
\hline Development Officer & $\mathrm{J}$ & July 2011 & Housing development \\
\hline Employer's Contractor & $\mathrm{K}$ & $\begin{array}{l}\text { September } \\
2010\end{array}$ & Housing construction \\
\hline Maintenance Officer & $\mathrm{L}$ & $\begin{array}{l}\text { September } \\
2010\end{array}$ & Housing management \\
\hline Maintenance Officer & M & $\begin{array}{l}\text { September } \\
2010\end{array}$ & Housing management \\
\hline $\begin{array}{l}\text { Regional } \\
\text { Development }\end{array}$ & $\mathrm{N}$ & June 2010 & Housing development \\
\hline
\end{tabular}




\begin{tabular}{|c|c|c|c|}
\hline Manager & & & \\
\hline $\begin{array}{l}\text { Regional Operation } \\
\text { Manager }\end{array}$ & 0 & $\begin{array}{l}\text { September } \\
2010\end{array}$ & Housing management \\
\hline $\begin{array}{l}\text { Social Regeneration } \\
\text { Officer }\end{array}$ & $\mathrm{P}$ & June 2011 & Resident liaison and support \\
\hline Surveyor & Q & $\begin{array}{l}\text { September } \\
2010\end{array}$ & Housing maintenance \\
\hline $\begin{array}{l}\text { Sustainability } \\
\text { Consultant }\end{array}$ & $\mathrm{R}$ & $\begin{array}{l}\text { October } \\
2010\end{array}$ & $\begin{array}{l}\text { Advises on the incorporation of low and zero- } \\
\text { carbon technologies in housing design }\end{array}$ \\
\hline $\begin{array}{l}\text { Sustainability } \\
\text { Consultant }\end{array}$ & $\mathrm{S}$ & $\begin{array}{l}\text { October } \\
2010\end{array}$ & $\begin{array}{l}\text { Advises on the incorporation of low and zero- } \\
\text { carbon technologies in housing design }\end{array}$ \\
\hline
\end{tabular}


Table 2. Points Scoring System (Code for Sustainable Homes Category 1 Energy/C02)

\begin{tabular}{|c|c|c|}
\hline Issue & Measurement Criteria & $\begin{array}{l}\text { Points } \\
\text { Awarded }\end{array}$ \\
\hline \multirow[t]{2}{*}{$\begin{array}{l}\text { Ecolabelled } \\
\text { white goods }\end{array}$} & $\begin{array}{l}\text { EITHER } \\
\text { Where fridges, freezers and fridge/freezers have an A+ rating } \\
\text { under EU Energy Efficiency Labelling Scheme }\end{array}$ & EITHER 1.2 \\
\hline & $\begin{array}{l}\text { AND OPTIONALLY Where washing machines and dishwashers } \\
\text { have an A rating and/or washer driers and tumble driers have a B } \\
\text { rating under EU Energy Efficiency Scheme } \\
\text { OR } \\
\text { Information is provided on purchasing and benefits of efficient } \\
\text { white goods, where such goods are not supplied within the new } \\
\text { home }\end{array}$ & $\begin{array}{l}\text { AND } \\
\text { OPTIONALLY + } \\
1.2\end{array}$ \\
\hline $\begin{array}{l}\text { Low or Zero } \\
\text { Carbon } \\
\text { Energy } \\
\text { Technologies }\end{array}$ & $\begin{array}{l}\text { EITHER } \\
\text { Where at least } 10 \% \text { of total energy demand is supplied from local } \\
\text { renewable or low carbon energy sources }\end{array}$ & EITHER 1.2 \\
\hline & $\begin{array}{l}\text { OR } \\
\text { Where at least } 15 \% \text { of total energy demand is supplied from local } \\
\text { renewable or low carbon energy sources }\end{array}$ & OR 2.4 \\
\hline
\end{tabular}

Source: Code for sustainable homes: a step-change in sustainable home building practice, December 2006: 13-14. 


\section{Endnotes}

${ }^{\mathrm{i}}$ Sustainability consultants are frequently employed by building developers to advise on how best to meet the sustainability requirements of particular local councils 